\title{
Monitoring and Real Time Diagnosis of Diabetes
}

\author{
JS R ao* \\ Department of Bioinformatics, The Vibration Institute of India, India
}

Submission: April 07, 2017; Published: May 30, 2017

"Corresponding author: JS Rao, Department of Bioinformatics, President, The Vibration Institute of India, Bangalore 560097, India, Email: rao_js@yahoo.com

\section{Abstract}

Human diagnostics and machine diagnostics follow the same principles. Machinery diagnostics has progressed considerably to real time expert systems based on the continuous monitoring to protect machinery, yet human diagnostics remains in the hands of specialist doctors. In fact machinery diagnostics has moved to the reality of Prognostics with a possible prediction of life within few seconds providing a margin to save the machine. A parallel between the two systems is drawn first and the possibility of real time diagnostics for humans remotely is suggested based on machinery diagnostics advances.

Keywords: Human diagnostics; Machinery Diagnostics; Diabetes; Sensors; Fault-symptom relationship; Expert System

Abbreviations: GOx: Glucose Oxidase; RBS: Random Blood Sugar Levels; ICU: Intensive Care Unit

\section{Introduction}

In the best possible scenario, a human being under distress due to natural or manmade conditions, the effected human being, patient, is carried to a nearby repair shop, hospital, before experts, doctors, attend to set right things if possible, else we lose the human being. A reverse scenario is possible in calling the experts or doctors to the scene of the patient in performing the diagnosis and taking corrective steps in saving the subject. Human beings are known to exist millions years ago.

Machines are rather very primitive relatively and created to serve the human beings. The power plants that produce electricity are developed first in 1884 only, yet they seem to attract more attention in protecting them from failures from the humans. The sensors have been developed almost simultaneously in $20^{\text {th }}$ century for both the machines as well as humans. The technology to save the machine (Asset Management) has advanced considerably, ironically developed by humans; the main reason behind is solely due to commercial aspects. Though we generally accept that the humans have in general a life span of 100 years, we tend to succumb to this reality and let things happen in a natural way to human beings.

We can bring the latest technologies to save human beings just the way we try to do to machinery. Here, we compare the existing scenario in both the cases and show how we can bring in the technological advances to humans from the mechanical world.

\section{Human Diagnostics}

In human diagnostics, let's take the case of Diabetes Mellitus, metabolic diseases in which there are high blood sugar levels over a prolonged period. Symptoms of high blood sugar include frequent urination, increased thirst, and increased hunger. If left untreated, diabetes can cause many complications, such as diabetic ketoacidosis in type 1 , nonketotic hyperosmolar coma, predominantly in type 2 diabetes. Long-term complications include heart disease, stroke, chronic kidney failure, foot ulcers, and damage to the eyes.

Diabetes is due to either the pancreas not producing enough insulin or the cells of the body not responding properly to the insulin produced. Type 1 results from the pancreas's failure to produce enough insulin, the case of juvenile diabetes; Type 2 begins with insulin resistance, a condition in which cells fail to respond to insulin properly, adult-onset diabetes; Type 3 is Gestational diabetes that occurs when pregnant women without a previous history of diabetes develop high blood sugar levels.

Over 400 million people, roughly $8 \%$ of the adult population in the world are reported to be affected by diabetes [1]. Type 2 cases alone are estimated to be about $90 \%$ of these. In the United States [2], diabetes cost $\$ 245$ billion in 2012 .

\section{Current States of Measurement}

Home Blood Glucose Monitoring (HBGM) [3]: It determines the approximate concentration of glucose in the 
blood of an individual, see Fig. 1. A small drop of blood, obtained by pricking the skin with a lancet, is placed on a disposable test strip that the meter reads and uses to calculate the blood glucose level. Clark presented his first paper about the oxygen electrode, later named the Clark electrode. In 1962, Clark and Ann Lyons from the Cincinnati Children's Hospital developed the first glucose enzyme electrode. This biosensor was based on a thin layer of glucose oxidase (GOx) on an oxygen electrode. Thus, the readout was the amount of oxygen consumed by GOx during the enzymatic reaction with the substrate glucose (Figure 1) [4]. Usually a patient is asked to take these measurements at fasting times in the morning (FBS) and two hours after breaking fast (Postprandial) and Random Blood Sugar Levels (RBS) etc. based on which doctors prescribe medication or direct injection of insulin.

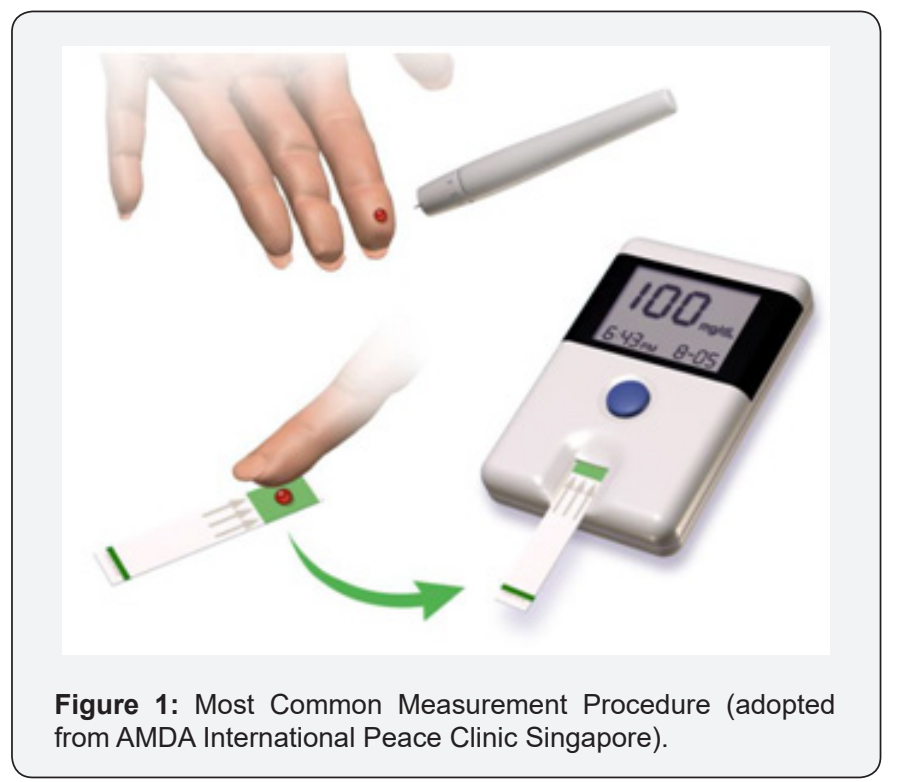

Continuous Glucose Monitoring (CGM) [5,6]: The CGM systems (Figure 2) generally involve the use of

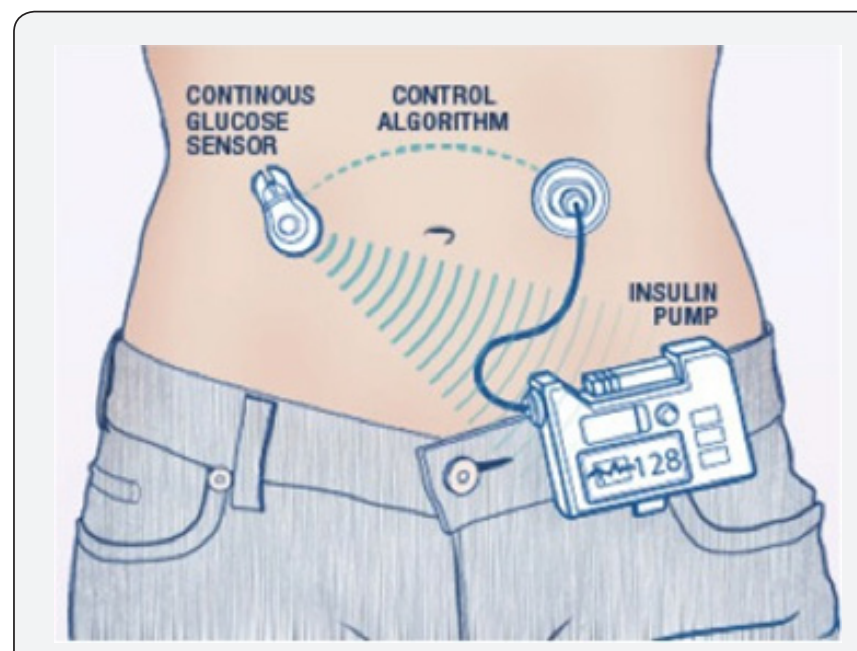

Figure 2: Continuous Glucose Monitoring System (adopted from [6]). a. a glucose sensor that detects changes in blood glucose levels within the body

b. a transmitter to relay blood glucose information to

c. a receiver

The measured glucose level is displayed on the receiver continuously. The receiver also contains insulin and an insulin pump and a tube that is inserted subcutaneously into the patient. The CGM system has a control algorithm to release the required amount of insulin necessary to maintain the target level of blood glucose. The CGM systems can also give an audible alarm, if blood glucose levels become too low or too high (Figure 2).

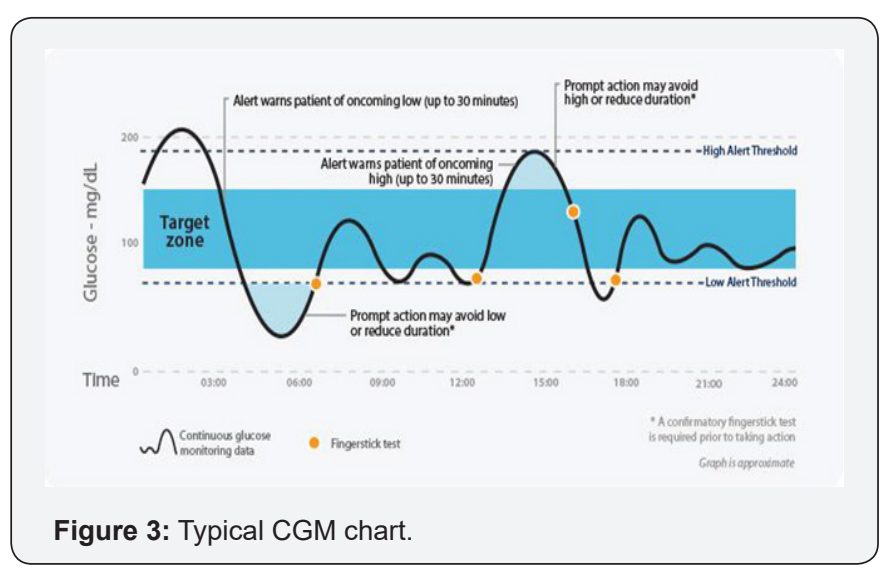

Current state of CGM applications: Figure 3 shows a typical CGM data that is obtained over a day. To validate the CGM data, four results from finger prick tests are also included during this time. The target zone is also shown in this chart with High and Low alert thresholds. Alert warns of oncoming low as well as high are also given to the person with the CGM system; these warns help in taking prompt actions necessary.

Present day human diagnostics on diabetes: The diabetic problems in humans are much more complex; only the current available instrumentation that helps doctors is presented. Individually simple diagnostics is provided by means of HBGM or CGM methods as the case may be. When a complex case involving, say, blood pressure and blood glucose are involved or still more complex cases where cardio problems are also involved, the current method of diagnostics is provided by an expert or team of experts. As an example, sliding scale therapy may be devised in simple and new cases that refer to the progressive increase in the pre-meal or nighttime insulin dose, based on pre-defined blood glucose ranges. Sliding scale insulin regimens approximate daily insulin requirements. This should not be used for existing cases of insulin intake; only experienced doctors can fix them up. There are no expert systems that can adopt diagnosis as a guidance based on the remote collection of data of humans in yet inaccessible regions. For example, villages where the population is affected by diabetes due to modern stress related problems or otherwise. Let us consider the failure of machines and how 
the detection and remedial process is done today; broadly called asset management.

\section{Machinery Diagnostics}

Jean-Victor Poncelet, a French military engineer and later professor at the École d' Application in Metz published his monograph on Introduction à la mécanique industrielle in 1829 [7]. In his lectures at the military school in Metz around 1837-1839, he for the first time referred to metals under stress as being "tired". He introduced the notion of fatigue of metals characterized by a drop in durability of steel products under repeated variable loads. The point is-it is not only living organisms that have memory; actually metal may possess the same function. Metals and machines made of these metals behave like living organisms and therefore they also die, when they are fatigued or tired. Their failure is expensive too and we need to protect them, the same way we try and protect humans (living organisms).

Ever since de Laval's impulse turbine was discovered together with Edison's dynamo the world has changed with electric power plants, land, air and sea transportation and space exploration amongst other things; it is rotating machinery everywhere [8]. This has brought in diagnostics of these machines using condition monitoring with appropriate sensors, recorders, displays, expert systems [9] with remote condition monitoring and prognostics [10].

While both the systems follow similar principles for protections, the technology with which humans are designed (we don't know the designers, we try to understand them) and machines are designed are different. We know the machines somewhat better, because we are the designers.

\section{Vibratory sensors}

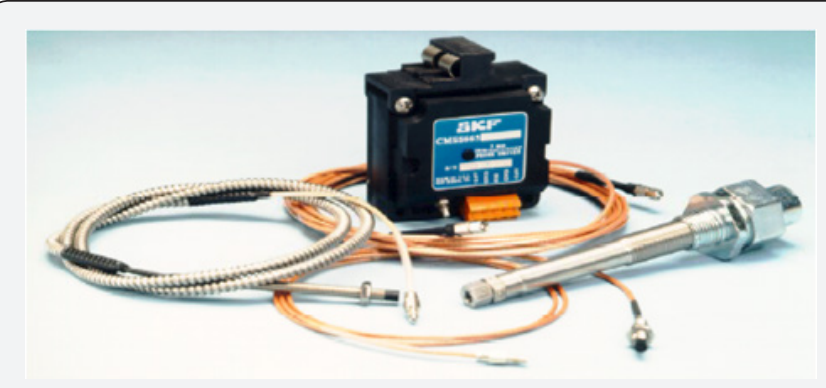

Figure 4: Eddy Probe for non-contact measurement.

Eddy probes: Figure 4, Measure Relative Distance between two surfaces.

Velocity transducer: Figure 5, Measure Bearing Housings or Machinery Casing Vibration, they are Electro-Mechanical Devices with Moving Parts that can Stick or Fail.

Accelerometer: Figure 6 Measure accelerations and are rugged devices. These sensors are similar to human diagnostics sensors, they sense what they are designed for Figure 7 is a read out based on sensors, similar to Human diagnostics in Figure $1 \& 2$. Individual machines in power plants or other installations can be monitored by placing an accelerometer on its bearing to find out what is wrong with it. This is similar to using a thermometer with a patient suffering from fever or using a Sphygmomanometer to measure blood pressure, or using a Stethoscope to find whether the heart is beating properly (Figure 8). Complex machinery have several rotors, a High Pressure rotor, Intermediate Pressure rotor (sometimes two) and a Low Pressure rotor (again two of them can be in machine). Each of these rotors is mounted in two bearings, where we can have sensors for identifying whether the machine is functioning well or not.
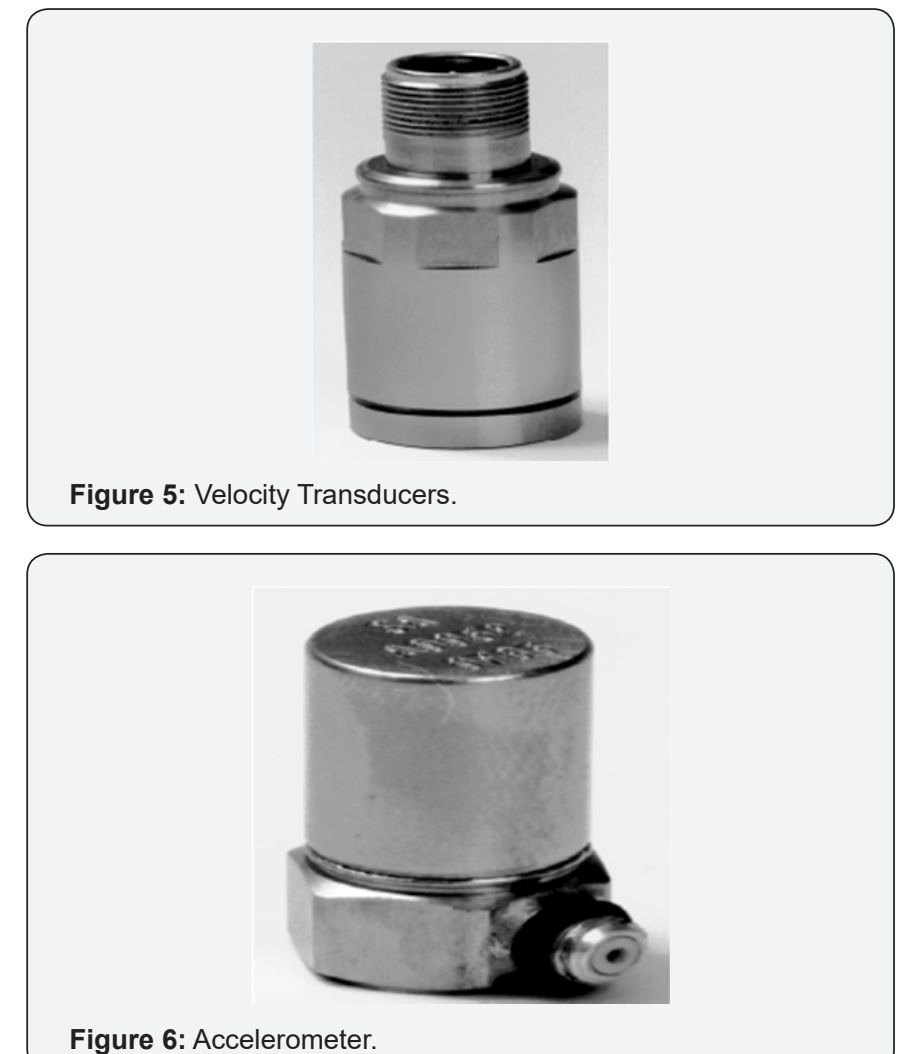

Figure 6: Accelerometer.

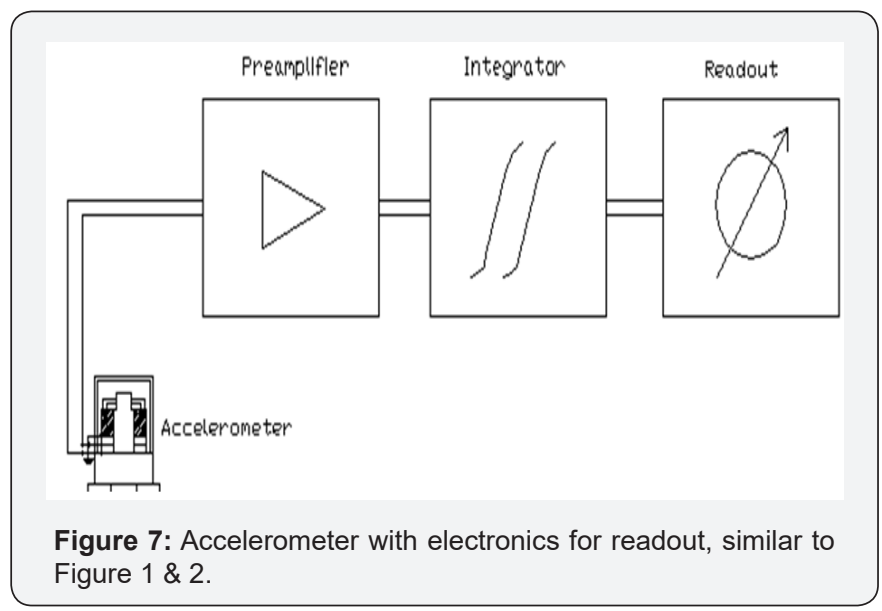




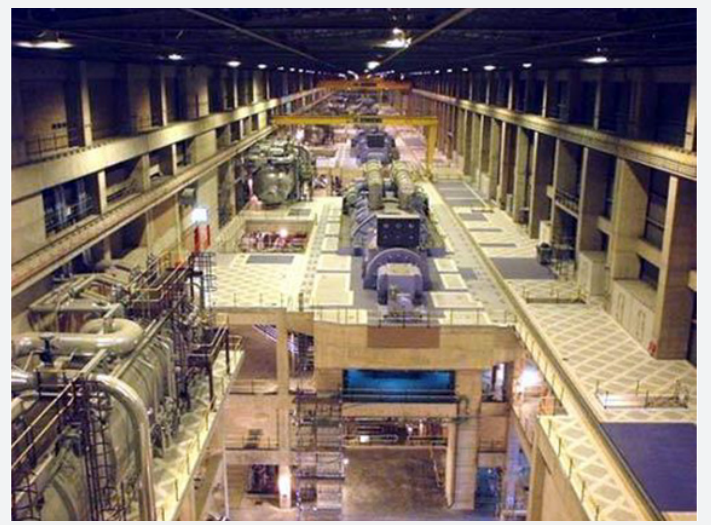

Figure 8: Majuba Coal Fired Power Plant, South Africa.

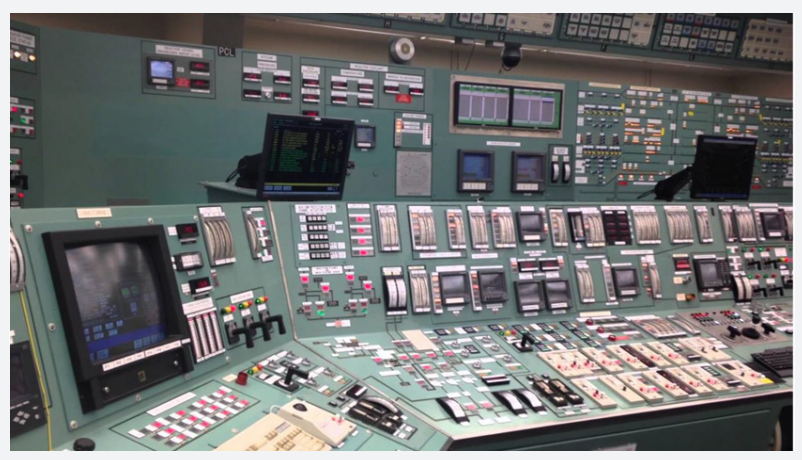

Figure 9: Training Control Room of a Nuclear Power Plant (Three Mile Island).

Thus one machine may have three sensors (or more). There could be 25 to 30 sensors of different varieties on a single machine that are wired into the control room with displays to help the operators run the machine properly, Figure 9. Similarly, Intensive care unit (ICU) equipment includes patient monitoring, respiratory and cardiac support, pain management to care for patients threatened by critical illness requiring 24-hour care and monitoring. As in power plant control rooms, a Nurse (or nurses) monitor a central station for intensive care unit (ICU) equipment (Figure 10).

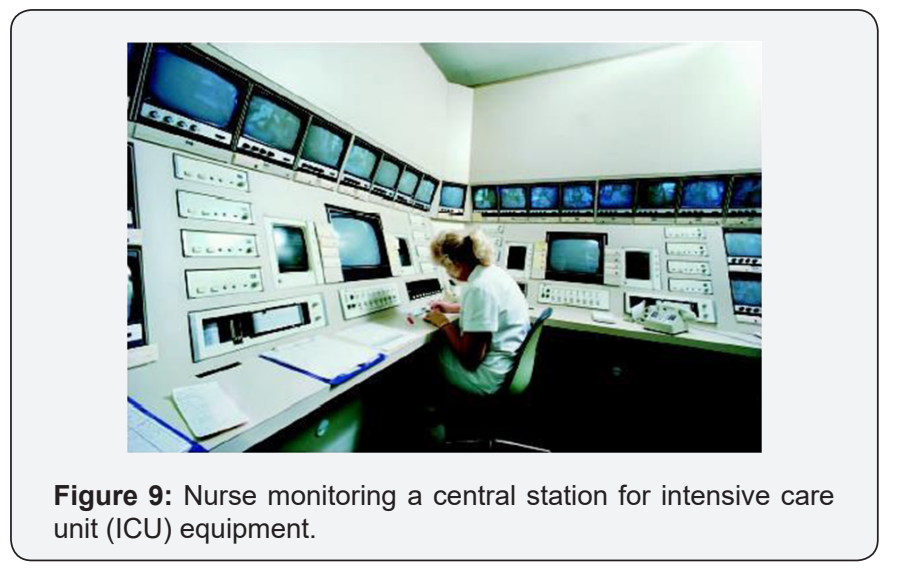

\section{Advances in Machinery Diagnostics}

There are practically no advances made in real time diagnostics and expert systems. Human diagnostics have seen miniaturized integrated devices, namely; the implantable Wireless Bio-Sensors (WBSs), the wearable WBSs and the handheld WBSs [11]. In Machinery diagnostics, however, some of the latest technologies were developed and absorbed.

Machinery and Humans (all living beings) have periodic phenomena; the machines depend on a cycle of operation and humans have heart beat, pulse rate etc. all repetitive in nature. Machinery diagnostics have taken advantage of Fourier transform and with the help of modern computers that can perform these calculations instantaneously. With this advantage data bases have been generated.

There are several faults likely both humans and machines can develop and the corresponding symptoms generated by sensors can be quickly compared to identify the likely fault. Such an expert system was developed in [12] and worked well in Nuclear power plants of India.

\section{The faults in a machine can be written down as}

a. Rotor unbalance

b. Reciprocating unbalance

c. Permanent bow (Bent shaft or warped shaft)

d. Rolling element bearing damage

e. Oil film excited vibrations

f. Casing or Foundation distortion

g. Steam whirl

h. Seal rub and Rotor axial rub

i. Insufficient tightness in assembly of:

j. Rotor (shrink-fits), Bearing liner, case,

k. Casing and support

l. Misalignment

m. Instabilities due to kinematic constraints

n. Cracks

o. Gear inaccuracy or damage

These defects shown in machine as symptoms that can be related to responses measured form the data base in developing the expert system [9]. A sample knowledge base is shown in Figure 11 based on extensive experience and data base collected. This forms the inference engine of an expert system.

A similar list can be consolidated for human diagnostics. One such study is from Mayo clinic [13]. Stress symptoms may be affecting one's health, even though the individual might not 
realize it. One may think that illness is to be blamed for a nagging headache, frequent insomnia or the decreased productivity at work. But stress may actually be the culprit.

\section{Common effects of stress}

Indeed, stress symptoms can affect the body, thoughts and feelings, and behavior. Being able to recognize common stress symptoms can give a jump on managing them. Stress that's left unchecked can contribute to many health problems, such as high blood pressure, heart disease, obesity and diabetes.

\section{Common effects (symptoms) of stress on your body}

a. Headache

b. Muscle tension or pain

c. Chest pain

d. Fatigue

e. Change in sex drive

f. Stomach upset

g. Sleep problems

\section{Common effects (symptoms) of stress on your mood}

a. Anxiety

b. Restlessness

c. Lack of motivation or focus d. Feeling overwhelmed

e. Irritability or anger

f. Sadness or depression

\section{Common effects of stress on your behavior}

a. Overeating or under eating

b. Angry outbursts

c. Drug or alcohol abuse

d. Tobacco use

e. Social withdrawal

f. Exercising less often

Compared with Machinery diagnostics advances, the development of a relation between measurements and symptoms is perhaps missing. The reasons for this may be manifold and will not be speculated here. First let us see how Machinery Diagnostics field has developed the expert system and put into use.

\section{Expert Systems in Machinery Diagnostics}

Rao [14] demonstrated its capability via internet in real time diagnosis of a machine run in Bangalore, India during an Acsim conference in Cairns, Australia. This paper is published in [15]. The development of expert system is based on the data collected over years by Sohre [16] and described in (Figure 11) [9].

\begin{tabular}{|c|c|c|c|c|c|c|c|c|c|c|c|}
\hline \multicolumn{12}{|c|}{$\%$ Cases Showing Vibration Frequency Symptoms for the Listed Causes } \\
\hline $\begin{array}{l}\text { Vitration Analysis } \Omega \\
\text { Causes of Vibration }\end{array}$ & $\begin{array}{c}\text { Reso } \\
\text { nank } \\
\text { freq }\end{array}$ & $40 \%$ & \begin{tabular}{|l|}
$50-$ \\
$100 \%$
\end{tabular} & $\begin{array}{l}1 \mathrm{x} \\
\mathrm{xpm}\end{array}$ & $\begin{array}{ll}2 \mathrm{x} \\
\mathrm{xpm}\end{array}$ & $\begin{array}{c}\text { higher } \\
\text { rpm } \\
\text { rpm }\end{array}$ & $\begin{aligned} 1 / 2 \\
\mathrm{xpm}\end{aligned}$ & $\begin{array}{l}1 / 4 \\
\mathrm{xpm}\end{array}$ & $\begin{array}{c}\text { lower } \\
\mathbf{x} \\
\mathrm{rpm}\end{array}$ & $\begin{array}{l}\text { odd } \\
\text { freq }\end{array}$ & $\begin{array}{l}\text { very } \\
\text { high } \\
\text { freq }\end{array}$ \\
\hline Initial unbalance & 5 & & & $\infty$ & 5 & 5 & & & & & \\
\hline $\begin{array}{l}\text { Permanent bow or } \\
\text { lost rotor parts }\end{array}$ & 30 & & & $\infty$ & 5 & 5 & & & & & \\
\hline Temporary rotor bow & 20 & & & $\infty$ & 5 & 5 & & & & & \\
\hline Casing distortion & 10 & 10 & 10 & $\infty$ & 20 & 10 & & & & & \\
\hline Foundation distortion & & 20 & & 40 & 30 & & & & & 10 & \\
\hline Seal rub & 10 & 10 & 10 & 20 & 10 & 10 & & & 10 & 10 & 10 \\
\hline Rotor axial rub & 20 & 20 & 20 & 30 & 10 & 10 & & & 10 & 10 & 10 \\
\hline Mis alignment & 5 & 10 & & 30 & 60 & 10 & & & & & 10 \\
\hline Piping forces & 5 & 10 & & 30 & $\infty$ & 10 & & & & & 10 \\
\hline $\begin{array}{l}\text { Joumal and bearing } \\
\text { eccentriciry }\end{array}$ & $\infty$ & & & 40 & 60 & & & & & & \\
\hline Bearing damage & 20 & 20 & 20 & 40 & 20 & & & & & & 20 \\
\hline $\begin{array}{l}\text { Beaning excited vituration } \\
\text { - oll whir } 1 \text { etc. }\end{array}$ & 20 & 6 & & & & & 10 & 10 & & & \\
\hline $\begin{array}{l}\text { Unequal } x \text { and } y \\
\text { bearng stiffmess }\end{array}$ & so & & & & so & 20 & & & & & \\
\hline $\begin{array}{l}\text { Thrust bearing } \\
\text { damage }\end{array}$ & $\infty$ & 90 & $\infty$ & $\infty$ & $\infty$ & & & & & & \\
\hline $\begin{array}{l}\text { Insufficient righmess } \\
\text { In assembly to ht } \\
\text { Rotor (shrink-firs) } \\
\text { Bearing limer } \\
\text { Bearimg case } \\
\text { Casing and support }\end{array}$ & $\begin{array}{l}40 \\
\infty \\
\infty \\
90\end{array}$ & $\begin{array}{l}40 \\
90 \\
90 \\
90\end{array}$ & 10 & $\begin{array}{l}10 \\
30 \\
30\end{array}$ & 10 & 10 & & & & $\begin{array}{l}10 \\
10 \\
10 \\
\text { so }\end{array}$ & \\
\hline $\begin{array}{l}\text { Gear inaccuracy or } \\
\text { damage }\end{array}$ & & & & & & 20 & & & $\begin{array}{c}\text { Mesh } \\
\text { freq }\end{array}$ & 20 & $\infty$ \\
\hline $\begin{array}{l}\text { Coupling inaccuracy } \\
\text { or damage }\end{array}$ & 10 & 20 & 10 & 20 & 30 & 10 & & & $\begin{array}{c}\text { Mesh } \\
\text { freq }\end{array}$ & 80 & $\$ 0$ \\
\hline Aerodynamic Excitation & 60 & 20 & & 20 & & & & & & 10 & 10 \\
\hline Critical speed & 100 & & & 100 & & & & & & & \\
\hline Structural res onance & 100 & 10 & & 70 & 10 & & 10 & & & & \\
\hline \begin{tabular}{|l} 
Pressure puls ations \\
\end{tabular} & 80 & & $m$ & 2 & esom & if com & in & th resc & nances & & \\
\hline Oal seal induced vibm & 30 & 70 & & & & & & & & & \\
\hline
\end{tabular}


Briefly this expert system is explained as follows. The first screen that pops up is given in Figure 12, called Operator Support and Backup Data Display. A similar screen depicting Human Expert System can be displayed the beginning if such an expert system is developed (Figure 13).

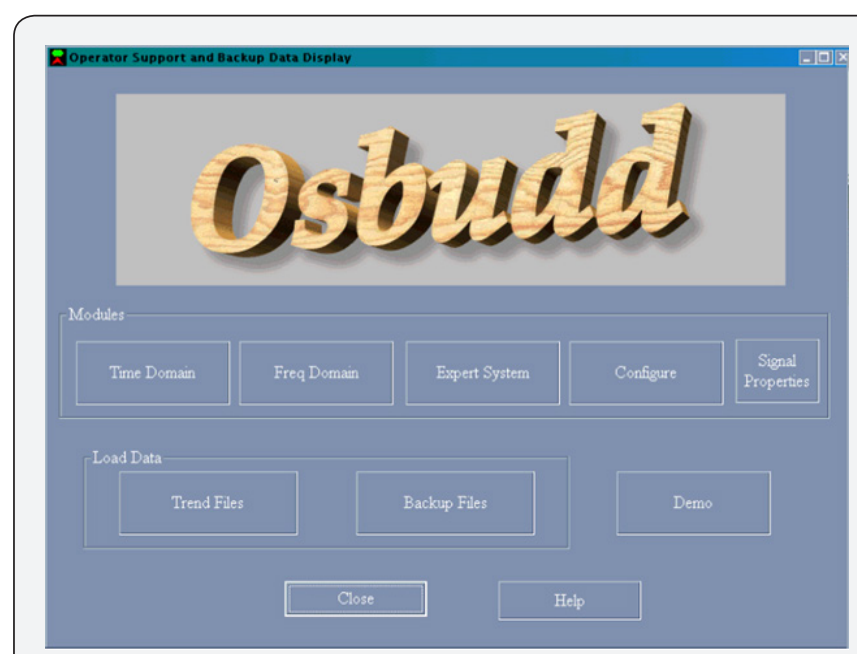

Figure 12: Operator Support and Backup Data Display Main Screen.

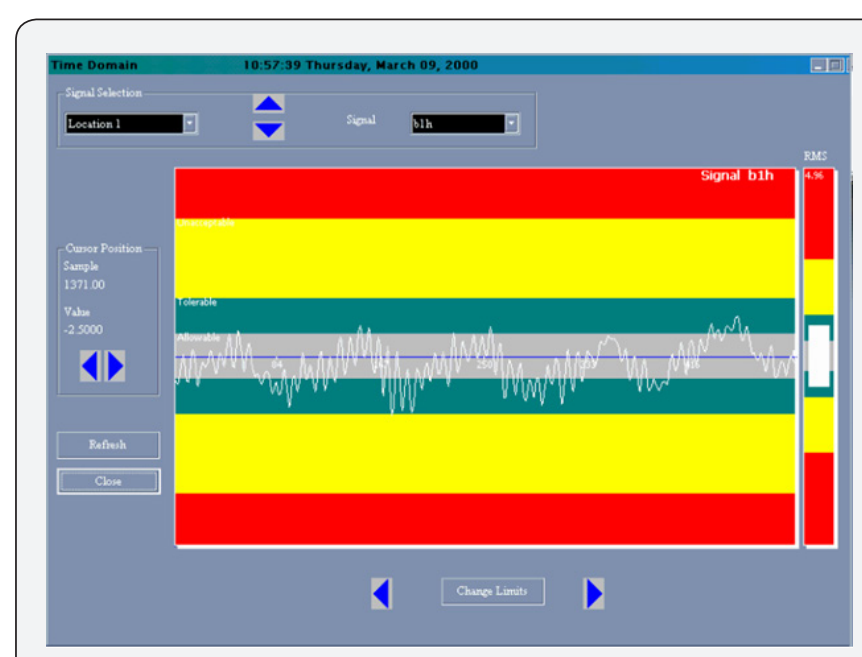

Figure 13: Time domain signal vibration of bearing 1 in horizontal direction.

The time domain signal is drawn continuously similar to Figure 3. There the signal does not vary periodically, however if the pressure signal from heart is continuously plotted it will vary periodically similar to Figure 13 having several harmonics. Note that the allowable, tolerable, not acceptable and dangerous levels are marked by color bands (Figure $14 \& 15$ ).

As noted before the time domain signal is repetitive in nature and a FFT analysis (instantaneously) provides the harmonics present in the signal of the machine that relates to possible trouble source. Figure 14 shows these harmonics with allowable color bands (Figure 16).

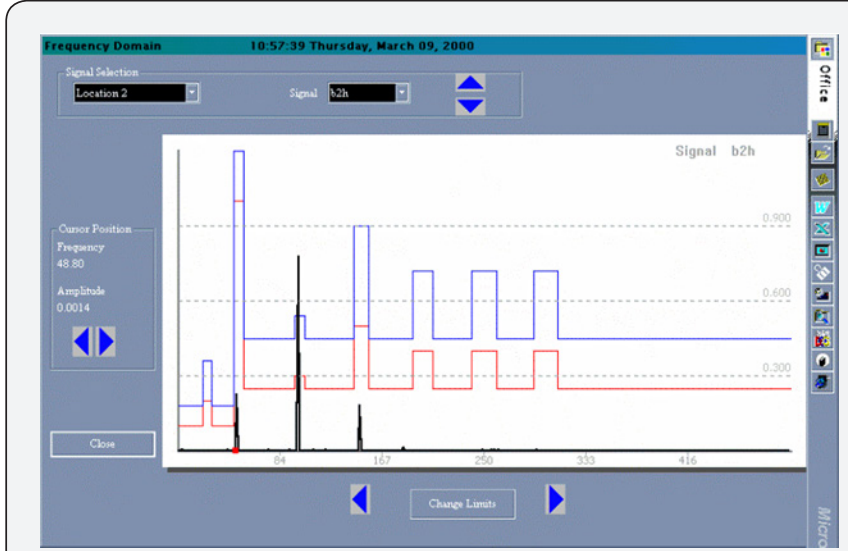

Figure 14: Frequency domain signal vibration of bearing 2 in horizontal direction.

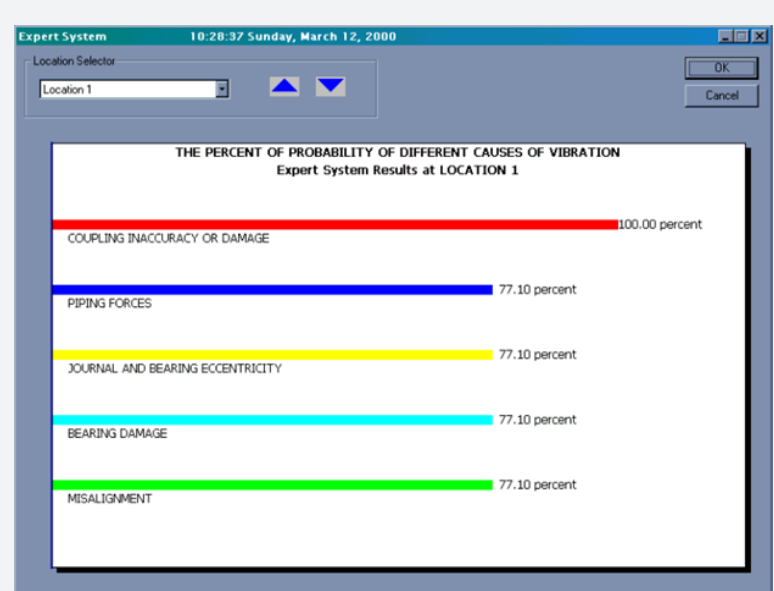

Figure 15: Expert System Results.

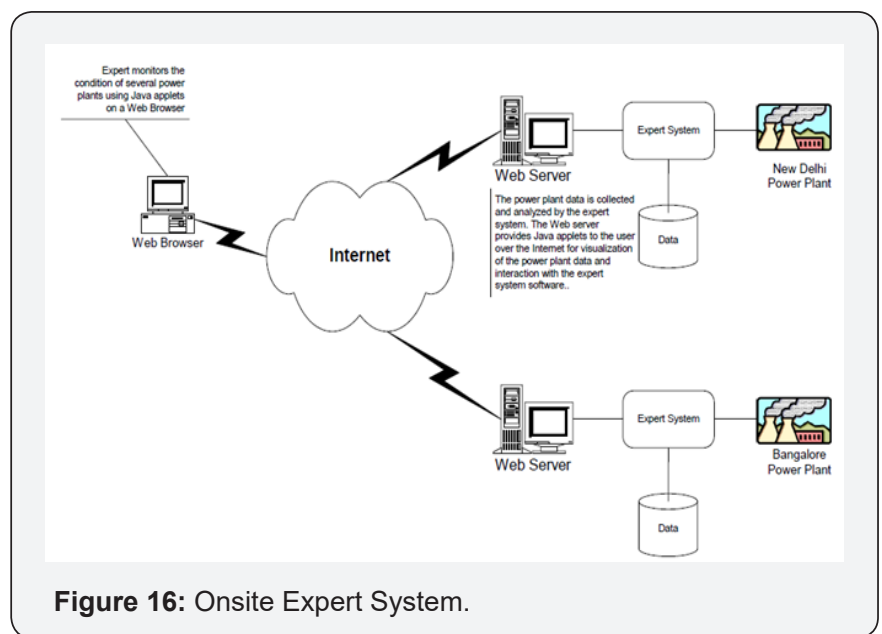

In human diagnostics, the measured quantity may reflect one of several problems, e.g., higher temperature of the body could be due to any number of defects. The diagnosis depends on a combination of existing factors, one arrives at a possible defect by experience or expertise or surrounding factors; in 
machinery diagnostics, and an expert system does the same. In other words, we do not have a single or unique relationship between the symptom and defect. It is based on the deduction using probabilities. Figure 15 shows the expert system result of a machine diagnostic from Osbudd.

The advantage of an expert system is an instantaneous result obtained even in the absence of a trained operator (or a doctor). In machine diagnostic systems, two separate systems are developed for convenience.

\section{a. Onsite Expert System as in Figure 16 and \\ b. Offsite Expert System Onsite Expert System as in Figure} 17.

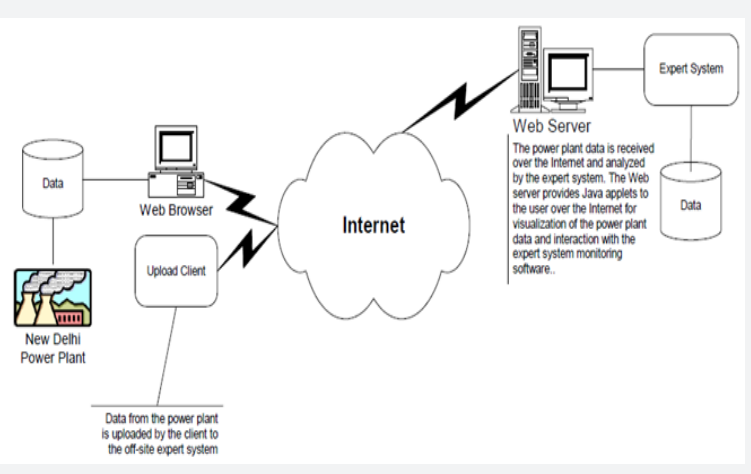

Figure 17: Offsite Expert System.

In the case of Human diagnostics, an expert can receive the data as well as the results and give his inputs without actually being present himself. This could have been very useful for the case that happened recently in case of a VVIP in Chennai hospital monitored by an expert all the way from a London hospital. Time and expenses could be considerably reduced and a patient can be easily saved (if it is feasible at all).

\section{A Simple Case to Begin With}

It is presumed that Expert System Diagnosis in Human Health monitoring is not well practiced. Diabetes case prevailing worldwide and individual attention given the present infrastructure in developing or poor countries being inadequate is discussed. Remote Expert system and advice can be an approach through which this problem can be adequately and affordably addressed.

\section{A project can be started with the following phases}

a. Adopt a group of villages served with poor medical infrastructure

b. Register (through Aadhaar card) people above, say, age c. Provide free CGM devises capable of sending data to the server in the parent hospital executing the project

d. Develop Expert Systems with collaborating partner or otherwise suggesting medications including insulin intake doses

The project may need to upgrade an existing local sickbay to have people trained with insertions of sensors and transmitters. Replicate these centers region wise to cover the entire population. Research hospitals may then generalize the Expert Systems to keep Expert Individually focused doctors to a minimum.

\section{References}

1. International Diabetes Federation Atlas ( $7^{\text {th }}$ edn) (2015).

2. American Diabetes Association(2013) Economic Costs of Diabetes in the US in 2012, Diabetes Care, Vol. 36(4): 1033-1046.

3. Blausen.com staff (2014) Medical gallery of Blausen Medical 2014. WikiJournal of Medicine 1(2).

4. Lipkowski J, Kolb DM, Alkire RC (2011) Bio electrochemistry: Fundamentals, Applications and Recent Developments. Wiley-VCH.

5. Alberto de LH, Eulalia BB, Alejandra de LP (2011) From pancreatic extracts to artificial pancreas: History, science and controversies about the discovery of the pancreatic antidiabetic hormone, VIII: Step by step towards the artificial pancreas, Av Diabetol 27(1): 27-38

6. Sarah Johnson, Alan Mann Tissue Engineered Pancreas.

7. Agarwal RP, Sen SK (2014) Creators of Mathematical and Computational Sciences, Springer.

8. Rao JS (2011) History of Rotating Machinery Dynamics, Springer.

9. Rao JS (2000) Vibratory Condition Monitoring of Machines-Narosa, 1999 (India), CRC Press (USA), Alpha Science (UK).

10. Rao JS (2017) Asset Management through Life Estimation, Keynote address, $12^{\text {th }}$ WCEAM and $13^{\text {th }}$ VETOMAC Joint conference, Brisbane, Australia, pp. 2-4.

11. Ebrahim GZ (2015) Wireless Integrated Biosensors for Point-of-Care Diagnostic Applications, Sensors 15(2): 3236-3261.

12. Rao JS (2000) Development of an Online Diagnostic system software for Turbo generator Set, Proc. Intl. Symposium on Machine Condition Monitoring and Diagnosis. JSME Annual Meeting 1(4): 18.

13. Mayo Clinic Staff (2016) Stress symptoms: Effects on your body and behavior.

14. Rao JS, Sharma S, Gupta T, Zubair M (2002) Online Diagnostics Using the Internet, ACSIM, Proc. $3^{\text {rd }}$ Asia Pacific Conference Systems Integrity and Maintenance, Cairns, p. 268.

15. Rao JS, Zubair M, Rao C (2003) Condition Monitoring of Power Plants through Internet, Integrated Manufacturing Systems: The International Journal of Manufacturing Technologies 14(6): 508.

16. Sohre JS (1991) Turbomachinery problems and their correction, Standardization and Condition Monitoring workshop (chapter 7) Houston. 
(C) Commons Attribution 4.0 License

DOI: $10.19080 / C T B E B .2017 .04 .555639$
Your next submission with Juniper Publishers will reach you the below assets

- Quality Editorial service

- Swift Peer Review

- Reprints availability

- E-prints Service

- Manuscript Podcast for convenient understanding

- Global attainment for your research

- Manuscript accessibility in different formats

( Pdf, E-pub, Full Text, Audio)

- Unceasing customer service

Track the below URL for one-step submission https://juniperpublishers.com/online-submission.php 